\title{
A Meta-Analysis of PCOS-Related Reproductive Abnormalities in Women Taking Valproate for Epilepsy
}

\section{Shumin Li}

Center for reproductive medicine, Shandong provincial hospital afflitated to Shandong University

\section{Shigang Zhao}

Center for reproductive medicine, Shandong provincial hospital afflitated to Shandong University

\section{Xueying Gao}

Center for Reproductive Medicine, Shandong provincial hospital afflitated to Shandong University

\section{Zhiheng Yu}

Center for Reproductive Medicine, Shandong provincial hospital afflitated to Shandong University

\section{Jinlong Ma}

Center for reproductive medicine, Shandong provincial hospital afflitated to Shandong University

\section{Ling Geng ( $\sim$ genglingsdu@163.com )}

Center for reproductive medicine, Shandong provincial hospital afflitated to Shandong University https://orcid.org/0000-0002-2560-5247

\section{Research}

Keywords: Valproate, Polycystic ovary syndrome, Epilepsy, Meta-analysis

Posted Date: January 5th, 2021

DOl: https://doi.org/10.21203/rs.3.rs-138898/v1

License: (a) This work is licensed under a Creative Commons Attribution 4.0 International License. Read Full License 


\section{Abstract}

Although a series of studies have been undertaken to clarify the effects of valproate (VPA) on reproductive endocrinology in female, no consistent conclusion has been reached. We aimed at quantifying the association between valproate (VPA) and reproductive endocrine abnormalities in women with epilepsy. We searched scientific literatures in English language published on electronic databases of PubMed, SinoMed and EMBASE before April 2020. These studies included were prospective and controlled. We then performed meta-analysis for polycystic ovary syndrome (PCOS) and its main characteristics in women with epilepsy treated with VPA. Results showed that there were statistically differences between the VPA treated and other AEDs group with epilepsy in PCOS ( $p<0.001,0 R 4.08,95 \%$ $\mathrm{Cl} 2.77-6.01), \mathrm{PCO}(\mathrm{p}<0.001, \mathrm{OR} 2.58,95 \% \mathrm{Cl} 1.90-3.51)$, hyperandrogenism ( $<<0.001, \mathrm{OR} 2.31,95 \% \mathrm{Cl}$ 1.66-3.23) and menstrual disorder ( $<<0.001$, OR 1.71, 95\% Cl 1.32-2.22). In conclusion, VPA chronic medication lead to higher risk of developing PCOS, PCO, hyperandrogenism and menstrual disorder in women with epilepsy.

\section{Introduction}

Epilepsy is one of the most common brain conditions, affecting over 70 million people worldwide and characterized by a lasting predisposition to generate spontaneous epileptic seizures[49]. Several articles illustrate an increased popularity of polycystic ovary syndrome (PCOS) in women with epilepsy[7], but whether it is induced by epilepsy itself or anti-epileptic drugs remains unclear yet. Valproate (VPA) is a spectrum antiepileptic drug, mainly used to treat generalized, partial or other specific epilepsy. In 1993, VPA was firstly announced to be associated with PCOS[26]. A series of studies reported that hyperandrogenism, menstrual disorders, polycystic ovary and other reproductive endocrine abnormalities were more prevalent in women taking VPA[1, 12, 19, 26,53]. Despite its many complications, a recent research published in 2020 has shown that VPA is irreplaceable and its avoidance/switch might be related with unsatisfactory seizure control in women with idiopathic generalized epilepsy who are of childbearing potential[9]. Therefore, we suggest that lifestyle counselling should be provided in women treated with VPA in order to prevent or treat PCOS. Besides, considering the treatment for PCOS, if women treated with VPA are affected with PCOS or its characteristics, they may consider taking drugs to improve the reproductive endocrine phenotype. However, there are several studies[3, 18, 55] displaying different results. Despite the publication of a paper on a similar topic[25], there has been no new meta-analysis in the last decade to summarize the effects of VPA on reproductive endocrinology as more clinical studies have emerged. Our aim was to perform the meta-analysis for evaluating the relationship between reproductive endocrine disorders and VAP medication in women with epilepsy.

\section{Methods}

Literature-search strategy 
A comprehensive search was performed for scientific literatures in English language in electronic databases of PubMed, SinoMed and EMBASE. The search strategy online was used as following: "Valproic Acid" [Mesh], valproate, valproic acid, "polycystic ovary syndrome" [Mesh], polycystic ovary syndrome, menstrual disorders, menstrual disturbances, reproductive endocrine disorders, reproductive endocrine function or dysfunction, reproductive endocrine, "Epilepsy" [Mesh], epilepsy.

\section{Inclusion and exclusion criteria}

We set the criteria by referring to a meta-analysis published in 2011[55] and made some adjustments as well as additions according to our own ideas.

The inclusion criteria: (1) published in English and full text were accessible; (2) Patients taking VPA and/or other AEDs for epilepsy and controls were included; (3) Patients were treated with VPA or other AEDs for at least one year; (4) Patients were all after menarche; (5) Patients were excluded if they had primary reproductive endocrine disorder (e.g. infertility or preceding history of PCOS), contraceptive medication or antipsychotics, gynecological or endocrine illnesses, pregnancy and lactation.

The exclusion criteria: (1) not writing in English, conference abstracts or reviews; (2) author(s) did not report VPA group and /or other drug group, respectively; (3) PCOS caused by VPA not in epilepsy, but in anxiety or bipolar disorder; (4) data were unavailable after corresponding with the author(s); (5) data were repeated.

\section{Data extraction}

Two authors searched and screened the titles, abstracts, and full-text articles independently. Both of them extracted useful information from each eligible study using uniform standards. After identifying the articles included in this study,we summarize the details of each literature, including the first author, date of publication, number of participants, study design, age of patients, number of patients, body mass index (BMI), duration (months), and dose (mg/day) of VPA if they were presented, and the detail information was shown in the table. If there was any divergence, all authors would discuss together to resolve the disagreement.

\section{Statistical analysis}

All meta-analyses were performed using Stata software version13 (Stata Corp, College Station, TX). The mean difference (MD) and 95\% confidence interval $(\mathrm{Cl})$ were used to compare continuous variables. We used the Mantel-Haenszel formula for repeated tests of independence and calculated a summary odds ratio. We quantified the effect of heterogeneity by using $\mathrm{I}^{2}$, ranging between $0 \%$ and $100 \%$, which represented the proportion of inter-study variability. If $\mathrm{I}^{2}>50 \%$, heterogeneity was unacceptable and random-effect model was performed to analyze the data. If $\mathrm{I}^{2}<50 \%$, heterogeneity was acceptable and fixed-effect model was performed to analyze the data. Besides, we evaluated the causes of heterogeneity via sensitivity analysis to assess the influence of each individual study on the pooled effect size by 
omitting each individual study. The funnel plot, a commonly used graphic test, as well as Egger's test and Begg's test, was used to assess publication bias qualitatively.

\section{Results}

A total of 226 articles were collected using the search strategy on electronic database PubMed, SinoMed and EMBASE with exception of 35 duplicated articles. Moreover, we excluded 21 case reports, 7 meeting abstracts, 70 reviews and meta-analysis, and some other irrelevant articles. These irrelevant articles included patients with bipolar disease, male patients, epilepsy management or VPA as comparator and so on. In this way, we got 21 full-text articles and assessed the eligibility. After screening each individual article, we extracted the key information and found there were two articles $[13,21]$ enrolling prepubertal girls, which did not meet our requirements. Besides, we also excluded four articles[36, 39, 44, 47] not providing enough useful data information in each group. Finally, fifteen articles[3, 5, 6, 16, 22, 23, 26, 27, $30-32,34,35,46,56]$ were included and their details were given in the table 1 . Although two studies had some of the same authors published in the same year, their subjects were recruited from different clinical centers. Hence, we considered that they were not repetitive. Figure 1 showed the flow diagram of the identification and screening of studies.

The fifteen studies included in this paper were prospective, involving 698 women with epilepsy treated with VPA, 927 women with epilepsy treated with other AEDs, 121 women with epilepsy untreated and 423 healthy women as controls. However, we emphasized that all end points were observed not only after menarche but also before menopause. Anti-epilepsy duration was no less than 6 months in order to explore the VPA effects on female reproductive endocrine system, including monotherapy and polytherapy. Except for VPA, carbamazepine (CBZ), lamotrigine (LTG), clonazepam (CNZ), primidone (PMD), phenytoin (PHT) and oxcarbazepine (OXP) were used as comparators, among which CBA and LTG were most common used. The patients involved in each individual study were not all available for PCOS and its components. There were 15 studies showing data in other AEDs treated women[5, 6, 16, 22, $23,26,27,30-32,34,35,46,56], 4$ studies showing data in untreated women $[5,13,23,34]$ and 5 studies showing data in healthy controls $[3,23,26,27,30]$.

At first, we compared the incidence of PCOS between VPA and other AEDs therapy table 2. Premature withdrawal and follow-up loss led to a major not all proportion of participants completing the study on PCOS. The PCOS incidence was $24.32 \%, 9.09 \%, 10.59 \%$ and $11.96 \%$ respectively in these four groups, VPA treated group, other AEDs group, untreated group and healthy controls. The statistic significant difference in PCOS was present between VPA treated and other AEDs treated group $(p<0.001,0 R 4.08$, 95\% Cl 2.77-6.01; in Fig 2). The symmetrical Begg's funnel plot indicated the almost absence of publication bias (Begg's Test, $p=1$ ) while Egger's publication bias plot showed the minor publication bias (Egger's Test, $\mathrm{p}=0.65$ ). Although the diagnostic criteria of PCOS have changed over years, $\mathrm{I}^{2}$ was $8.0 \%$, meaning that the effect of heterogeneity could be neglected. 
Then we compared the three critical features of PCOS in VPA treated group and other AEDs group. PCO was considered with 8-10 or more follicles and diameter 2-8mm in 6 studies[6, 22,30-32, 34], or with transvaginal or transabdominal (in the case with an intact hymen) each ovary existing with 12 or more follicles with size 2-9 mm in diameter and/or volume of ovary $>10 \mathrm{~mL}[3,13,46,56]$ as well a total of at least 10 cysts 2 to $8 \mathrm{~mm}$ in diameter[26,27]. One study defined ovaries as polycystic when $\geq 10-15$ cysts were seen in a single plane[23]. There is a significant difference of PCO between women treated with VPA and those without VPA ( $<<0.001$, OR 2.58, 95\% Cl 1.90-3.51; in Fig 3). Hyperandrogenism was a clinical and/or biochemical medical condition characterized by excessive production and/or secretion of androgens with symptoms including hirsutism, acne, alopecia and seborrhea. Women using VPA medication were more susceptible to hyperandrogenism and/or hyperandrogenemia than women using other AEDs ( $p<0.001, \mathrm{OR} 2.31,95 \% \mathrm{Cl} 1.66-3.23$; in Fig 4). Menstrual disorders meant the presence of any of the following for more than 6 months: amenorrhea (absence of menstruation), oligomenorrhea (cycle length longer than 35 days), irregular menstrual cycles (cycle length varying more than 4 days, between 21 and 35 days), and polymenorrhea (menstrual cycles lasting less than 21-25 days). VPA treated women were more susceptible to menstrual disorders than non-VPA treated women $(p<0.001,0 R 1.71,95 \% \mathrm{Cl}$ 1.32-2.22; in Fig 5).

Funnel plot and Begg's as well as Egger's test demonstrated that this meta-analysis would not be subject to publication bias. Cochrane $\mathrm{Q}$ test and $\mathrm{I}^{2}$ test did not show heterogeneity in PCOS in total (Fig 2). However, heterogeneity was presence in PCO (Fig 3), hyperandrogenism (Fig 4) and menstrual disorders (Fig 5) of VPA vs other AEDs according to $Q$ test $(p<0.1)$ and $\mathrm{I}^{2}$ test $(41.8 \%-73.0 \%)$. For sensitivity analysis of PCO, hyperandrogenism and menstrual disorders, the summary results would not change despite reduced heterogeneity. Finally, we also used a measurement tool AMSTAR 2 (Assess Systematic Reviews, http://www.amstar.ca/) to assess the quality of our meta-analysis and improved the content of our study according to AMSTR checklist. Based on the comprehensive literature search, we listed the excluded articles and justified the exclusions.

\section{Discussion}

Using the older, more restrictive criteria, the prevalence of PCOS in premenopausal is about $6 \%$ while applying current, more inclusive definitions $[2,4,11,14]$ it reaches $20 \%$. This phenomenon means that PCOS is likely to be the most common endocrine and metabolic disorder in women of reproductive age[17, 54]. Several recent studies have been devoted to investigate the link between epilepsy and PCOS, and raised a point that epilepsy itself might result in reproductive dysfunction and PCOS by deranging hypothalamic function as well as $\mathrm{GnRH}$ pulse generator, and by altering of LH pulsatility[7]. Others proposed that the common anti-epileptic drug, valproate, might be the leading cause of PCOS in epileptic patients[7]. In this meta-analysis, we summarized 11 clinical studies and found that women using VPA medication with epilepsy were much more subject to PCOS than other AEDs treated women. We did not compare the incidence of PCOS in VPA treated vs untreated group or VPA treated vs healthy controls for two reasons. First and foremost, there are few studies including those untreated or healthy participants 
simultaneously to compare with VPA treated women, leading to not enough data to draw a convincing conclusion. Secondly, if comparing with healthy controls, we cannot exclude the effects of epilepsy on hypothalamus-pineal-gland (HPG) axis. Likewise, if comparing with untreated epileptic women, the difference of seizure frequencies and epileptic control condition might exert different and potential impact on HPG axis as well. When comparing the risk of PCOS in between VPA treated and other AEDs treated group, the $\mathrm{I}^{2}$ is $8.0 \%$ and $\mathrm{p}$ value in Begg's test is 1 , indicating the negligible effects of heterogeneity and publication bias. We can draw a conclusion that VPA medication in women with epilepsy does result in the much higher risk of with PCOS.

Polycystic (multifollicular or polyfollicular) ovary is the main morphological change in PCOS whereas its incidence is about $20 \%$ of the general population ${ }^{[10]}$. Thereby, it is generally accepted that the isolated PCO should not be an abnormal feature[7]. It is usually detected by transvaginal or transabdominal ultrasound, sometimes by MRI. Different from one previous meta-analysis[55], we concluded that the prevalence of PCO in the VPA treated group in this meta-analysis was higher than other AEDs treated group. But we have to acknowledge the existence of heterogeneity because $\mathrm{I}^{2}$ is $57.7 \%$. The reasons for heterogeneity in our consideration were as follows. Firstly, women with hymen can only perform transabdominal ultrasound. In this way, the thickness of abdominal fat can affect the ultrasound judgement. Secondly, the experience of the sonologist also influenced the diagnosis of PCO. Besides, the PCO' definition has changed over decades. However, we can easily find the presence of the significant difference of PCO between women treated with VPA and those without VPA ( $p<0.001,0 R 2.58,95 \% \mathrm{Cl}$ 1.90-3.51). Therefore, we believe that the existence of these heterogeneity does not affect our speculation that VPA is a risk factor for PCO, nor will it be reversed. Furthermore, in non-epileptic rat, a 3-month VPA treatment was reported to contribute to a dose-dependent increase in the number of ovarian follicular cysts as well as decrease in the number of corpora lutea[42] and reproductive endocrine dysfunctions[48] which supported that VPA exerted impact on ovarian morphology alterations independent of antiepileptic activity. Nevertheless, in nonepileptic normal primates exposed to VPA treatment for 12 to 15 months, VPA treatment did not cause cyclic hormonal or ovarian morphological abnormalities or PCOS characteristics. The results from this research suggested that the direct effect of VPA instead of combination with effect of epilepsy needed to be taken into account[18].

Hyperandrogenism is defined by the clinical characteristics of hirsutism (Ferriman-Gallwey score 6), acne or alopecia, and/or elevated androgen level[43]. The prevalence of hirsutism and acne reaches around $12.2 \%$ in unselected premenopausal women[45], which is much lower than VPA-treated group. Recent studies[26, 29, 52, 55,56] and our meta-analysis all found that women with VPA treatment were frequently affected with hyperandrogenism. Moreover, it was interesting to note that young women seemed to be more vulnerable to the effects of VPA. If girls under 20 took VPA medication, the frequency of hyperandrogenism was great higher, leading to development to PCOS and pubertal arrest[8, 50]. But a recent study showed that higher testosterone levels were attributed from VPA treatment only after menarche, suggesting that the sensitivity to VPA-induced hyperandrogenism was a function of sexual maturation[12]. Besides free and total testosterone, the serum mean androgen levels were also increased 
in women exposed to VPA[28]. Interestingly, in spite of higher androgen levels in serum, there was no difference in hirsutism score in a previous study[37]. Herzog[24] regarded this phenomenon as protective results of the increased level of sex hormone binding globulin (SHBG) by enzyme-inducing activity. Not only long-term use, but also short-term use of VPA can cause similar changes[40]. Only one-month VPA medication on newly-diagnosed epilepsy female patients resulted in increased mean serum levels of testosterone, LH, FSH, and SHBG, and decreased dehydroepiandrosterone sulfate (DHEAS) though no weight gain or clinical signs of hormonal disorders were observed. Therefore, Rattya[40] concluded that women with increased serum testosterone levels in the early phase of VPA medication had higher risk to be affected with VPA-related endocrine disorders later during VPA treatment. However, not all studies[15]' [20] have proven that VPA promotes androgen production. As for mechanisms of VPA influencing androgen production, the most popular one is epigenetic modulation via inhibiting histone deacetylase (HDAC). In human ovarian thecal cell[38] exposure to VPA $(30-3000 \mu \mathrm{M})$ for $72 \mathrm{~h}$ produced much more DHEA and androstenedione comparing with control, with CYP17 upregulation and increased histone $\mathrm{H} 3$ acetylation. Besides, VPA was regarded as a stimulator of insulin secretion[41, 51]. Hyperinsulinemia induced by VPA stimulated ovarian (and adrenal) androgen production and increased androgen bioavailability through reduced levels of SHBG[33], leading to higher risk of hyperandrogenism in VPA treated women.

Menstrual disorder was more prevalent in VPA treated women with epilepsy $(p<0.001)$. Because of the presence of heterogeneity, we performed sensitivity analysis and figured that one study[23] had a kind of impact on heterogeneity. In this study, Hamed et. al[23] found that menstrual irregularities were identified in $60.2 \%(n=53)$ of patients and predominated among the treated group of patients, particularly with CBZ rather than VPA. When we identified different types of menstrual disorders in VPA and CBZ treated group, oligomenorrhea and menorrhagia were predominant among CBZ-treated group of patients while amenorrhea was predominant with VPA, possibly indicating that the effect of VPA on menstrual disorders was more severe than other AEDs. As VPA use has often been associated with weight increase, it has been suggested that weight gain could be the main pathogenic factor leading to reproductive endocrine disturbances. PCOS, hyperandrogenism and menstrual disorders were more common in obese than in lean women treated with VPA[27].

Limitations of our study should be mentioned in our meta-analysis. We could not acquire enough information from included studies about the difference between VPA monotherapy and VPA polytherapy. As well, we could not make a subgroup analysis for the possible roles according to different diagnostic criteria for insufficient data. The sensitivity analysis demonstrated meta-analysis confidence was influenced by inconsistent definitions of PCOS and its components and small samples.

\section{Conclusions}

According to clinical studies carried these years, VPA treated women with epilepsy had higher risk of not only PCOS, but also its components, PCOS, hyperandrogenism and menstrual disorders. When taking VPA for medication, close follow-up should be conducted to evaluate VPA effect on reproductive 
endocrinology and prevent the development of disorders. In addition, more homogeneous and prospective studies with large sample are needed to elucidate the effects and mechanisms of VPA on female reproductive endocrine system.

\section{Declarations}

\section{*Ethics approval and consent to participate}

Not applicable.

\section{*Consent for publication}

Not applicable.

\section{*Availability of data and materials}

Our research is a meta-analysis including clinical research published before 2020. It is present and appropriate for data policy associated with the journal.

\section{*Competing interests}

The authors declare that they have no conflicts of interest and the manuscript is submitted with the consent of all authors.

\section{*Funding}

This work was supported by the National Natural Science Foundation of Shandong Province (JQ201816), National Key Research and Development Program of China (2018YFC1004303), Key Research and Development Program of Shandong Province (2019GSF108274) and Young Scholars Program of Shandong University.

\section{*Authors' contributions-}

Shumin Li, Shigang Zhao, Xueying Gao and Zhiheng Yu have searched and screened the titles, abstracts, and full-text articles independently. All of them extracted useful information from each eligible study using uniform standards and identified the articles included in this study. Jinlong Ma, Ling Geng and Shigang Zhao have provided funding support and technical guidance.

\section{*Acknowledgements}

The authors would like to acknowledge Jinlong Ma, Ling Geng and Shigang Zhao for their invaluable help in the article.

\section{References}


1. Akdeniz F, Taneli F, Noyan A, Yuncu Z, Vahip S: Valproate-associated reproductive and metabolic abnormalities: are epileptic women at greater risk than bipolar women? Prog Neuropsychopharmacol Biol Psychiatry 2003, 27(1):115-121.

2. Asuncion M, Calvo RM, San Millan JL, Sancho J, Avila S, Escobar-Morreale HF: A prospective study of the prevalence of the polycystic ovary syndrome in unselected Caucasian women from Spain. $J$ Clin Endocrinol Metab 2000, 85(7):2434-2438.

3. Ayyagari M, Chitela SR, Kolachana V: Obesity, polycystic ovarian syndrome and thyroid dysfunction in women with epilepsy. Ann Indian Acad Neurol 2012, 15(2):101-105.

4. Azziz R, Woods KS, Reyna R, Key TJ, Knochenhauer ES, Yildiz BO: The prevalence and features of the polycystic ovary syndrome in an unselected population. J Clin Endocrinol Metab 2004, 89(6):27452749.

5. Bauer J, Jarre A, Klingmuller D, Elger CE: Polycystic ovary syndrome in patients with focal epilepsy: a study in 93 women. Epilepsy Res 2000, 41(2):163-167.

6. Betts T, Yarrow H, Dutton N, Greenhill L, Rolfe T: A study of anticonvulsant medication on ovarian function in a group of women with epilepsy who have only ever taken one anticonvulsant compared with a group of women without epilepsy. Seizure 2003, 12(6):323-329.

7. Bilo L, Meo R: Epilepsy and polycystic ovary syndrome: where is the link? Neurol Sci 2006, 27(4):221230.

8. Bodensteiner JB: Valproate-induced hyperandrogenism during pubertal maturation in girls with epilepsy. Clin Pediatr (Phila) 1999, 38(11):681-683.

9. Cerulli Irelli E, Morano A, Cocchi E, Casciato S, Fanella M, Albini M, Avorio F, Basili LM, Fisco G, Barone FA et al: Doing without valproate in women of childbearing potential with idiopathic generalized epilepsy: Implications on seizure outcome. Epilepsia 2020, 61(1):107-114.

10. Clayton RN, Ogden V, Hodgkinson J, Worswick L, Rodin DA, Dyer S, Meade TW: How common are polycystic ovaries in normal women and what is their significance for the fertility of the population? Clin Endocrinol (Oxf) 1992, 37(2):127-134.

11. Conway G, Dewailly D, Diamanti-Kandarakis E, Escobar-Morreale HF, Franks S, Gambineri A, Kelestimur F, Macut $D$, Micic D, Pasquali $R$ et al: The polycystic ovary syndrome: a position statement from the European Society of Endocrinology. Eur J Endocrinol 2014, 171(4):P1-29.

12. de Vries L, Karasik A, Landau Z, Phillip M, Kiviti S, Goldberg-Stern H: Endocrine effects of valproate in adolescent girls with epilepsy. Epilepsia 2007, 48(3):470-477.

13. de Vries L, Karasik A, Landau Z, Phillip M, Kiviti S, Goldberg-Stern H: Endocrine effects of valproate in adolescent girls with epilepsy. Epilepsia, 48(3):470-477.

14. Diamanti-Kandarakis E, Kouli CR, Bergiele AT, Filandra FA, Tsianateli TC, Spina GG, Zapanti ED, Bartzis Ml: A survey of the polycystic ovary syndrome in the Greek island of Lesbos: hormonal and metabolic profile. J Clin Endocrinol Metab 1999, 84(11):4006-4011.

15. Dutta S, Cloyd JC, Granneman GR, Collins SD: Oral/intravenous maintenance dosing of valproate following intravenous loading: a simulation. Epilepsy research 2003, 53(1-2):29-38. 
16. El-Khayat HA, Abd El-Basset FZ, Tomoum HY, Tohamy SM, Zaky AA, Mohamed MS, Hakky SM, El Barbary NS, Nassef NM: Physical growth and endocrinal disorders during pubertal maturation in girls with epilepsy. Epilepsia 2004, 45(9):1106-1115.

17. Escobar-Morreale HF: Polycystic ovary syndrome: definition, aetiology, diagnosis and treatment. Nat Rev Endocrinol 2018, 14(5):270-284.

18. Ferin M, Morrell M, Xiao E, Kochan L, Qian F, Wright T, Sauer M: Endocrine and metabolic responses to long-term monotherapy with the antiepileptic drug valproate in the normally cycling rhesus monkey. J Clin Endocrinol Metab 2003, 88(6):2908-2915.

19. Genton P, Bauer J, Duncan S, Taylor AE, Balen AH, Eberle A, Pedersen B, Salas-Puig X, Sauer MV: On the association between valproate and polycystic ovary syndrome. Epilepsia 2001, 42(3):295-304.

20. Glister C, Satchell L, Michael AE, Bicknell AB, Knight PG: The anti-epileptic drug valproic acid (VPA) inhibits steroidogenesis in bovine theca and granulosa cells in vitro. PLoS One 2012, 7(11):e49553.

21. Goldberg-Stern H, Yaacobi E, Phillip M, de Vries L: Endocrine effects of valproic acid therapy in girls with epilepsy: a prospective study. Eur J Paediatr Neurol 2014, 18(6):759-765.

22. Gorkemli H, Genc BO, Dogan EA, Genc E, Ozdemir S: Long-term effects of valproic acid on reproductive endocrine functions in Turkish women with epilepsy. Gynecologic and obstetric investigation 2009, 67(4):223-227.

23. Hamed SA, Hamed EA, Shokry M, Omar H, Abdellah MM: The reproductive conditions and lipid profile in females with epilepsy. Acta neurologica Scandinavica, 115(1):12-22.

24. Herzog AG: Polycystic ovarian syndrome in women with epilepsy: epileptic or iatrogenic? Annals of neurology 1996, 39(5):559-560.

25. Hu X, Wang J, Dong W, Fang Q, Hu L, Liu C: A meta-analysis of polycystic ovary syndrome in women taking valproate for epilepsy. Epilepsy Res 2011, 97(1-2):73-82.

26. Isojarvi JI, Laatikainen TJ, Pakarinen AJ, Juntunen KT, Myllyla VV: Polycystic ovaries and hyperandrogenism in women taking valproate for epilepsy. N Engl J Med 1993, 329(19):1383-1388.

27. Isojarvi JI, Tauboll E, Pakarinen AJ, van Parys J, Rattya J, Harbo HF, Dale PO, Fauser BC, Gjerstad L, Koivunen $\mathrm{R}$ et al: Altered ovarian function and cardiovascular risk factors in valproate-treated women. The American journal of medicine 2001, 111(4):290-296.

28. Isojarvi JIT, Tauboll E, Herzog AG: Effect of antiepileptic drugs on reproductive endocrine function in individuals with epilepsy. CNS Drugs 2005, 19(3):207-223.

29. Joffe H, Cohen LS, Suppes T, McLaughlin WL, Lavori P, Adams JM, Hwang CH, Hall JE, Sachs GS: Valproate is associated with new-onset oligoamenorrhea with hyperandrogenism in women with bipolar disorder. Biol Psychiatry 2006, 59(11):1078-1086.

30. Lofgren E, Mikkonen K, Tolonen U, Pakarinen A, Koivunen R, Myllyla VV, Tapanainen JS, Isojarvi Jl: Reproductive endocrine function in women with epilepsy: the role of epilepsy type and medication. Epilepsy Behav 2007, 10(1):77-83. 
31. Luef G, Abraham I, Haslinger M, Trinka E, Seppi K, Unterberger I, Alge A, Windisch J, Lechleitner M, Bauer G: Polycystic ovaries, obesity and insulin resistance in women with epilepsy. A comparative study of carbamazepine and valproic acid in 105 women. Journal of neurology 2002, 249(7):835841.

32. Luef G, Abraham I, Trinka E, Alge A, Windisch J, Daxenbichler G, Unterberger I, Seppi K, Lechleitner M, Kramer $\mathrm{G}$ et al: Hyperandrogenism, postprandial hyperinsulinism and the risk of PCOS in a cross sectional study of women with epilepsy treated with valproate. Epilepsy Res 2002, 48(1-2):91-102.

33. McCartney CR, Marshall JC: CLINICAL PRACTICE. Polycystic Ovary Syndrome. N Engl J Med 2016, 375(1):54-64.

34. Mikkonen KM, Vainionpaa LKMDP, Pakarinen AJMDP, Knip MMDP, Jarvela IYMDP, Tapanainen JSMDP, Isojarvi JIMDP: Long-term reproductive endocrine health in young women with epilepsy during puberty. Neurology 2004, 62(3):445-450.

35. Morrell MJ, Hayes FJ, Sluss PM, Adams JM, Bhatt M, Ozkara C, Warnock CR, Isojarvi J: Hyperandrogenism, ovulatory dysfunction, and polycystic ovary syndrome with valproate versus lamotrigine. Ann Neurol 2008, 64(2):200-211.

36. Morrell MJ, Isojarvi J, Taylor AE, Dam M, Ayala R, Gomez G, O'Neill F, Tennis P, Messenheimer J: Higher androgens and weight gain with valproate compared with lamotrigine for epilepsy. Epilepsy Res 2003, 54(2-3):189-199.

37. Murialdo G, Galimberti CA, Gianelli MV, Rollero A, Polleri A, Copello F, Magri F, Ferrari E, Sampaolo P, Manni R et al: Effects of valproate, phenobarbital, and carbamazepine on sex steroid setup in women with epilepsy. Clin Neuropharmacol 1998, 21(1):52-58.

38. Nelson-DeGrave VL, Wickenheisser JK, Cockrell JE, Wood JR, Legro RS, Strauss JF, 3rd, McAllister JM: Valproate potentiates androgen biosynthesis in human ovarian theca cells. Endocrinology 2004, 145(2):799-808.

39. Prabhakar S, Sahota P, Kharbanda PS, Siali R, Jain V, Lal V, Khurana D: Sodium valproate, hyperandrogenism and altered ovarian function in Indian women with epilepsy: a prospective study. Epilepsia, 48(7):1371-1377.

40. Rattya J, Pakarinen AJ, Knip M, Repo-Outakoski M, Myllyla VV, Isojarvi Jl: Early hormonal changes during valproate or carbamazepine treatment: a 3-month study. Neurology 2001, 57(3):440-444.

41. Reaven GM: Banting lecture 1988. Role of insulin resistance in human disease. Diabetes 1988 , 37(12):1595-1607.

42. Roste LS, Tauboll E, Berner A, Isojarvi JI, Gjerstad L: Valproate, but not lamotrigine, induces ovarian morphological changes in Wistar rats. Exp Toxicol Pathol 2001, 52(6):545-552.

43. Rotterdam EA-SPcwg: Revised 2003 consensus on diagnostic criteria and long-term health risks related to polycystic ovary syndrome (PCOS). Hum Reprod 2004, 19(1):41-47.

44. Sahota P, Prabhakar S, Kharbanda PS, Bhansali A, Jain V, Das CP, Modi M: Seizure type, antiepileptic drugs, and reproductive endocrine dysfunction in Indian women with epilepsy: a cross-sectional study. Epilepsia, 49(12):2069-2077. 
45. Sanchon R, Gambineri A, Alpanes M, Martinez-Garcia MA, Pasquali R, Escobar-Morreale HF: Prevalence of functional disorders of androgen excess in unselected premenopausal women: a study in blood donors. Hum Reprod 2012, 27(4):1209-1216.

46. Sidhu HS, Srinivasa R, Sadhotra A: Evaluate the effects of antiepileptic drugs on reproductive endocrine system in newly diagnosed female epileptic patients receiving either Valproate or Lamotrigine monotherapy: A prospective study. Epilepsy Res 2018, 139:20-27.

47. Stephen LJ, Kwan P, Shapiro D, Dominiczak M, Brodie MJ: Hormone profiles in young adults with epilepsy treated with sodium valproate or lamotrigine monotherapy. Epilepsia, 42(8):1002-1006.

48. Sveberg Roste L, Tauboll E, Isojarvi JI, Pakarinen AJ, Huhtaniemi IT, Knip M, Gjerstad L: Effects of chronic valproate treatment on reproductive endocrine hormones in female and male Wistar rats. Reprod Toxicol 2002, 16(6):767-773.

49. Thijs RD, Surges R, O'Brien TJ, Sander JW: Epilepsy in adults. Lancet 2019, 393(10172):689-701.

50. Vainionpaa LK, Rattya J, Knip M, Tapanainen JS, Pakarinen AJ, Lanning P, Tekay A, Myllyla VV, Isojarvi Jl: Valproate-induced hyperandrogenism during pubertal maturation in girls with epilepsy. Annals of neurology 1999, 45(4):444-450.

51. Vorum H, Gram L, Honore B: Valproate and palmitate binding to serum albumin in valproate-treated patients. Relation to obesity. Epilepsy Res 1993, 16(1):55-64.

52. Watanabe K, Kikuchi T: [Adverse events of psychotropic drugs]. Seishin Shinkeigaku Zasshi 2014, 116(4):323-331.

53. Wood JR, Nelson-Degrave VL, Jansen E, McAllister JM, Mosselman S, Strauss JF, 3rd: Valproateinduced alterations in human theca cell gene expression: clues to the association between valproate use and metabolic side effects. Physiol Genomics 2005, 20(3):233-243.

54. Yildiz BO, Bozdag G, Yapici Z, Esinler I, Yarali H: Prevalence, phenotype and cardiometabolic risk of polycystic ovary syndrome under different diagnostic criteria. Hum Reprod 2012, 27(10):3067-3073.

55. Zhang L, Li H, Li S, Zou X: Reproductive and metabolic abnormalities in women taking valproate for bipolar disorder: a meta-analysis. Eur J Obstet Gynecol Reprod Biol 2016, 202:26-31.

56. Zhou JQ, Zhou LM, Chen LJ, Han JD, Wang Q, Fang ZY, Chen ZY, Ling S: Polycystic ovary syndrome in patients with epilepsy: a study in 102 Chinese women. Seizure 2012, 21(9):729-733.

\section{Tables}

Table 1 Detailed information of the included studies. 


\begin{tabular}{|c|c|c|c|c|c|c|c|c|c|}
\hline Study & Study design & Age & $\begin{array}{l}\text { Therapy } \\
\text { duration }\end{array}$ & Therapy dose (mg/d) & $\begin{array}{c}\text { Pla sma } \\
\text { concentration }\end{array}$ & With VPA & Other AEDs & Untreated & $\begin{array}{l}\text { Healthy } \\
\text { controls }\end{array}$ \\
\hline Jouko 1993 & Prospective, crosssectional & $18-45 y$ & $0-31 y$ & $1043 \pm 306$ & $65 \pm 30 \mathrm{mg} / \mathrm{L}$ & 41 & 182 & 15 & None \\
\hline Bauer 2000 & Prospective, crosssectional & $20-50 \mathrm{y}$ & No data & Mean 1414 & No data & 34 & 40 & 19 & None \\
\hline Jouko 2001 & Prospective, international, multicenters & $31 \pm 6 y$ & $\geq 18 \mathrm{~m}$ & $1116 \pm 400$ & No data & 37 & 35 & None & 52 \\
\hline Luef $_{1} 2002$ & Prospective, crosssectional & $16-40 \mathrm{y}$ & $\geq 2 y$ & 1250 & No data & 22 & 21 & None & None \\
\hline Luef $_{2} 2002$ & Prospective, crosssectional & $16-40 y$ & $\geq 2 y$ & 957 & No data & 52 & 53 & None & None \\
\hline Betts 2003 & Prospective, crosssectional & No data & $\geq 1 \mathrm{y}$ & No data & No data & 54 & 51 & None & 50 \\
\hline $\begin{array}{l}\text { El-Khayat's } \\
2004\end{array}$ & Prospective, cohort & $8-18$ y & $1-5 y$ & No data & No data & 31 & 35 & None & 40 \\
\hline Löfgren 2007 & Post Hoc reanalysis & $18-40 y$ & $>1 \mathrm{y}$ & $1100 \pm 384$ & $273.1 \pm 273.1 \mu \mathrm{mol} / \mathrm{L}$ & 55 & 93 & None & 170 \\
\hline Hamed 2007 & Prospective, crosssectional & $18-45 y$ & $\geq 6 \mathrm{~m}$ & Mean $687.5(400-1200)$ & No data & 18 & 32 & 15 & 60 \\
\hline Morrell 2008 & Prospective, international, multicenters & $13-40 \mathrm{y}$ & $1 \mathrm{y}$ & 1000 & No data & 222 & 225 & None & None \\
\hline $\begin{array}{l}\text { Gorkemli } \\
2009\end{array}$ & Prospective, crosssectional & $17-39 y$ & $24-43 \mathrm{~m}$ & $500-2000$ & No data & 40 & 31 & None & None \\
\hline Mythili 2012 & Prospective, crosssectional & $13-45 y$ & $\geq 6 \mathrm{~m}$ & $645 \pm 270.9$ & No data & 20 & 40 & None & None \\
\hline $\begin{array}{l}\text { Jue-Qian } \\
2012\end{array}$ & Prospective, crosssectional & $12-45 y$ & $2.8 \pm 3.3 \mathrm{y}$ & $14.175 \mathrm{mg} /$ day $/ \mathrm{kg}$ & No data & 32 & 40 & 30 & None \\
\hline $\begin{array}{l}\text { Harpreet } \\
2018 \\
\end{array}$ & Prospective & $14-42$ y & $1 \mathrm{y}$ & $1240(400-2000)$ & $50-112 \mathrm{mg} / \mathrm{L}$ & 30 & 32 & None & None \\
\hline
\end{tabular}

Table 2 Comparisions and stratified analysis of PCOS in VPA treated, other AEDs treated, untreated patients and healthy controls.

\begin{tabular}{|c|c|c|c|c|c|c|c|c|c|c|c|c|}
\hline \multirow{2}{*}{ Study } & \multicolumn{3}{|c|}{ With VPA } & \multicolumn{3}{|c|}{ Other AEDs } & \multicolumn{3}{|c|}{ Untreated } & \multicolumn{3}{|c|}{ Healthy controls } \\
\hline & PCO & HA & MD & PCO & HA & MD & PCO & HA & MD & PCO & HA & MD \\
\hline Jouko 1993 & $8 / 31$ & $3 / 31$ & $16 / 41$ & $8 / 67$ & $0 / 67$ & $31 / 182$ & None & $0 / 15$ & $0 / 15$ & None & None & $8 / 51$ \\
\hline Bauer 2000 & None & None & $8 / 34$ & None & None & $13 / 40$ & None & None & None & None & None & None \\
\hline Jouko 2001 & $23 / 37$ & $10 / 37$ & None & $5 / 35$ & $6 / 35$ & None & None & None & None & $9 / 52$ & $3 / 52$ & None \\
\hline Luef $_{1} 2002$ & $5 / 22$ & $3 / 22$ & $5 / 22$ & $6 / 21$ & $6 / 21$ & $7 / 21$ & None & None & None & None & None & None \\
\hline Luef $_{2} 2002$ & $13 / 52$ & $3 / 52$ & $12 / 52$ & $15 / 53$ & $1 / 53$ & $17 / 53$ & None & None & None & None & None & None \\
\hline Betts 2003 & $27 / 54$ & None & None & $17 / 51$ & None & None & None & None & None & $3 / 50$ & None & None \\
\hline Mikkonen 2004 & $7 / 10$ & $7 / 10$ & None & $8 / 17$ & $4 / 17$ & None & None & None & None & $9 / 36$ & None & None \\
\hline Lofgren 2007 & $25 / 55$ & $19 / 55$ & $24 / 55$ & $21 / 93$ & $12 / 93$ & $28 / 93$ & None & None & None & $36 / 170$ & $7 / 170$ & $49 / 170$ \\
\hline Hamed 2007 & $10 / 18$ & $8 / 18$ & $10 / 18$ & $3 / 32$ & $4 / 32$ & $29 / 32$ & $13 / 15$ & $6 / 15$ & $11 / 15$ & $10 / 60$ & $0 / 60$ & $13 / 60$ \\
\hline Morrell 2008 & None & $44 / 143$ & $48 / 154$ & None & $19 / 120$ & $29 / 145$ & None & None & None & None & None & None \\
\hline Gorkemli 2009 & $22 / 40$ & $15 / 40$ & $29 / 40$ & $14 / 31$ & $7 / 31$ & $13 / 31$ & None & None & None & None & None & None \\
\hline Mythili 2012 & $8 / 20$ & $4 / 20$ & $12 / 20$ & $6 / 40$ & $13 / 40$ & $9 / 40$ & None & None & None & $3 / 20$ & $3 / 20$ & $5 / 20$ \\
\hline Jue-Qian 2012 & $16 / 32$ & $5 / 32$ & $13 / 32$ & $8 / 40$ & $2 / 40$ & $4 / 40$ & None & None & None & None & None & None \\
\hline Harpreet 2018 & $5 / 30$ & $8 / 30$ & $9 / 30$ & $1 / 32$ & $1 / 32$ & $2 / 32$ & None & None & None & None & None & None \\
\hline
\end{tabular}

PCO: polycystic ovary; HA: hyperandrogenism or hyperandrogenemia; MD: menstrual disorder

Table 3 PCOS' components for stratified analysis in VPA treated and other AEDs treated patients and healthy controls. 


\begin{tabular}{|c|c|c|c|c|}
\hline Study & $\begin{array}{l}\text { With VPA } \\
\text { PCOS }\end{array}$ & $\begin{array}{l}\text { Other AEDs } \\
\text { PCOS }\end{array}$ & $\begin{array}{l}\text { Untreated } \\
\text { PCOS }\end{array}$ & $\begin{array}{l}\text { Healthy controls } \\
\text { PCOS }\end{array}$ \\
\hline Jouko 1993 & None & None & None & None \\
\hline Bauer 2000 & $2 / 34$ & $2 / 40$ & $2 / 19$ & None \\
\hline Jouko 2001 & None & None & None & None \\
\hline Luef $_{1} 2002$ & $2 / 22$ & $1 / 21$ & None & None \\
\hline Luef $_{2} 2002$ & None & None & None & None \\
\hline Betts 2003 & $16 / 54$ & $3 / 51$ & None & $7 / 50$ \\
\hline El-Khayat 2004 & $5 / 31$ & $3 / 13$ & None & None \\
\hline Mikkonen 2004 & $6 / 10$ & $4 / 17$ & $3 / 42$ & $4 / 36$ \\
\hline Lofgren 2007 & $27 / 55$ & $15 / 93$ & None & $19 / 170$ \\
\hline Hamed 2007 & None & None & None & None \\
\hline Morrell 20082 & $17 / 186$ & $4 / 177$ & None & None \\
\hline Gorkemli 2009 & $25 / 40$ & $10 / 31$ & None & None \\
\hline Mythili 2012 & $6 / 20$ & $6 / 40$ & None & $3 / 20$ \\
\hline Jue-Qian 2012 & $11 / 32$ & $2 / 40$ & None & None \\
\hline Harpreet 2018 & $8 / 30$ & $0 / 27$ & None & None \\
\hline
\end{tabular}

\section{Figures}




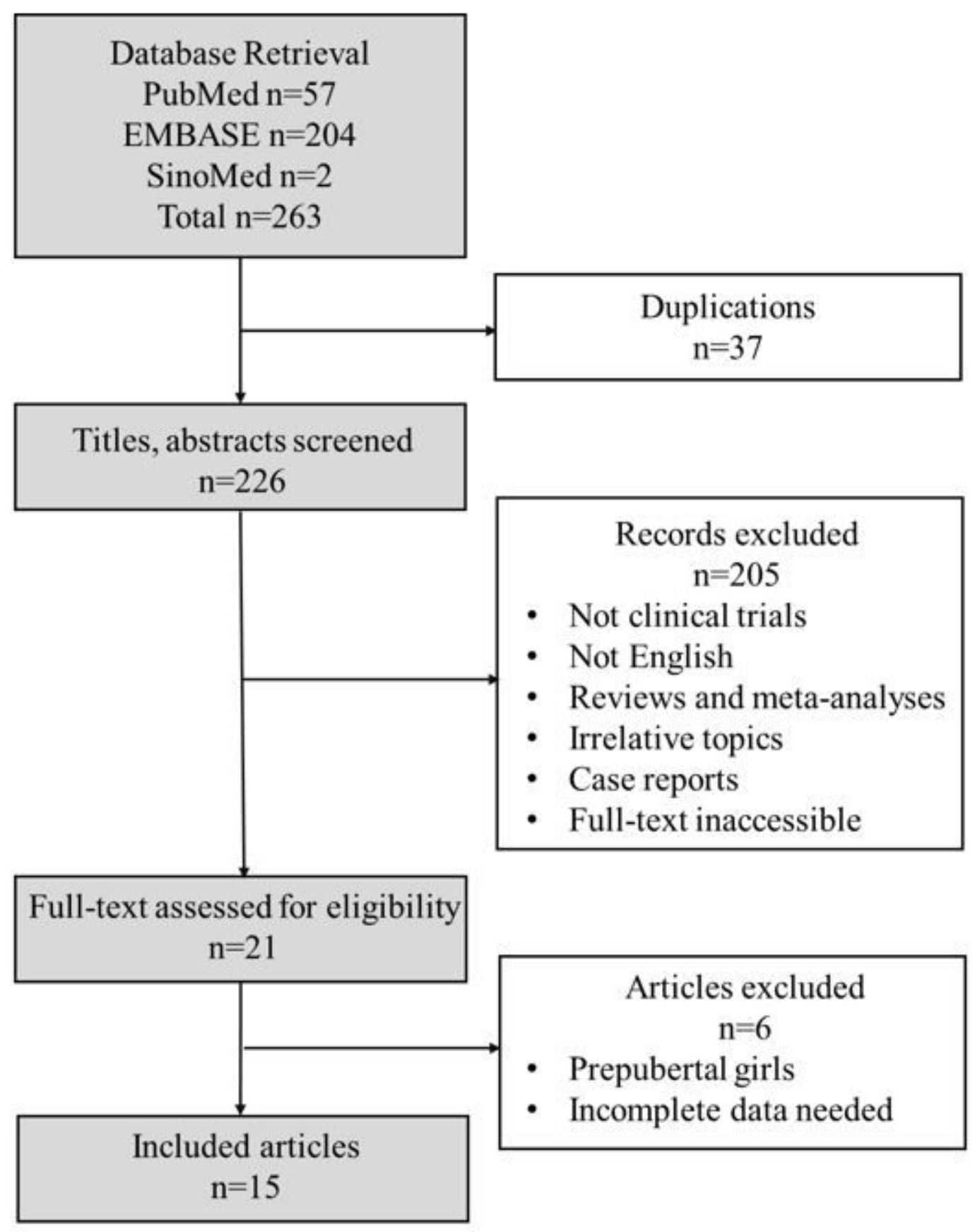

Figure 1

Flow chart of article selection. 
a. Forest plot

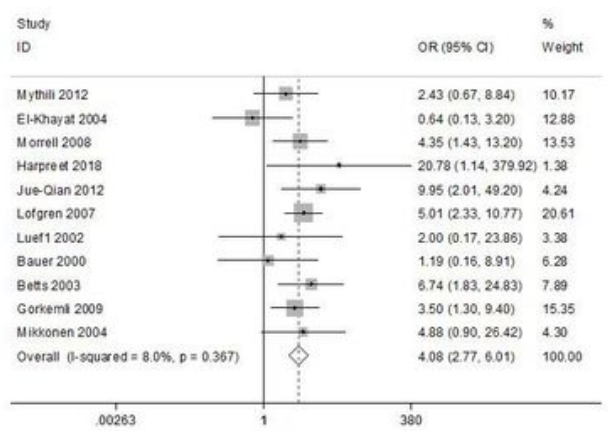

b. Begg's test

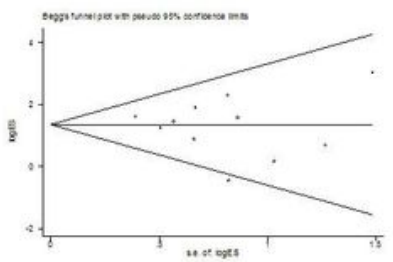

c. Egger's test

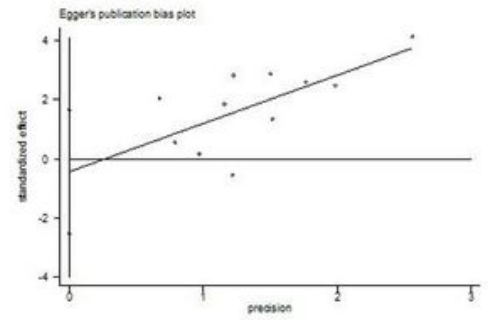

d. Fumnel plot
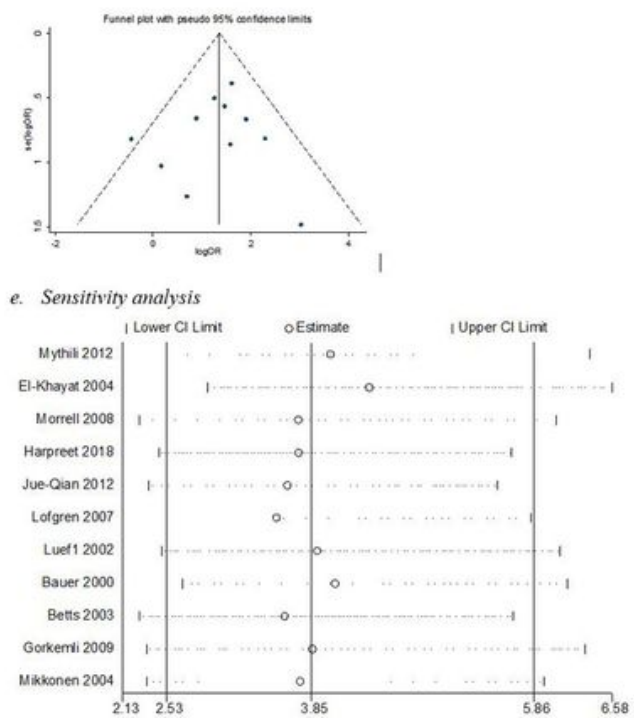

Figure 2

PCOS of VPA vs other AEDs, accepting different definitions of PCOS. 
a. Forest plot

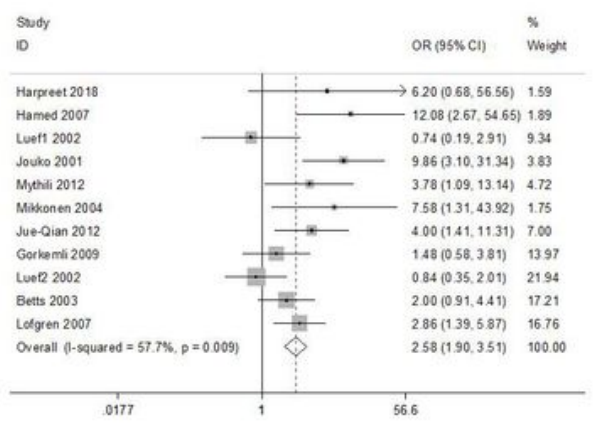

b. Begg's test

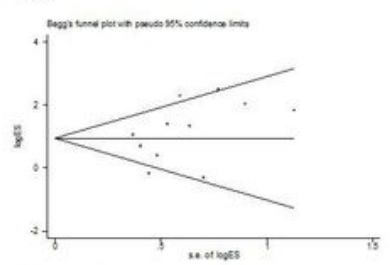

c. Egger's test

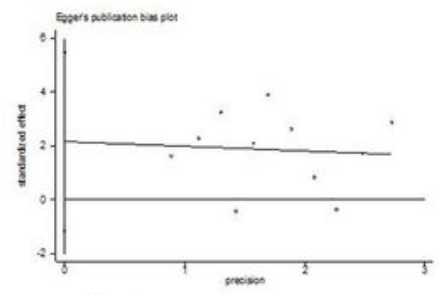

d. Funnel plot

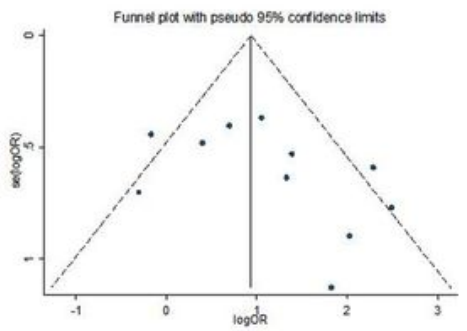

e. Sensitivity analysis

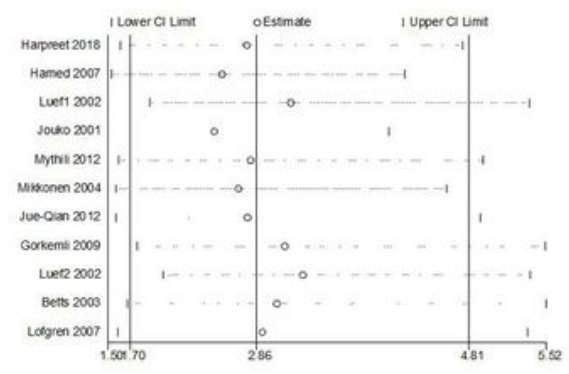

\section{Figure 3}

PCO of VPA vs other AEDs 
a. Forest plot

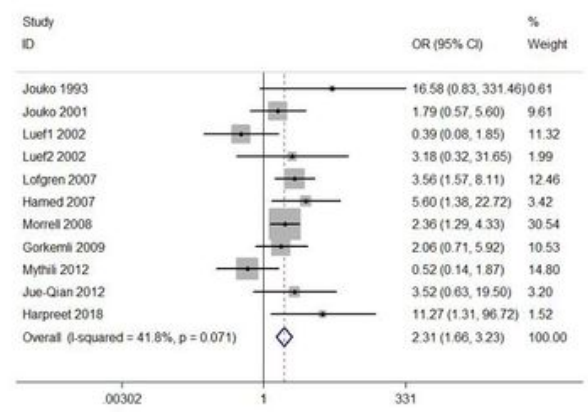

b. Begg's test

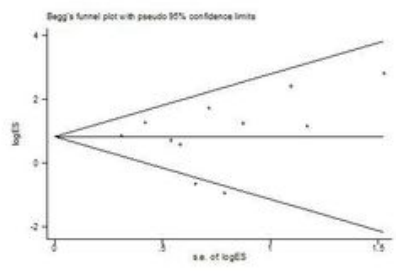

c. Egger's test

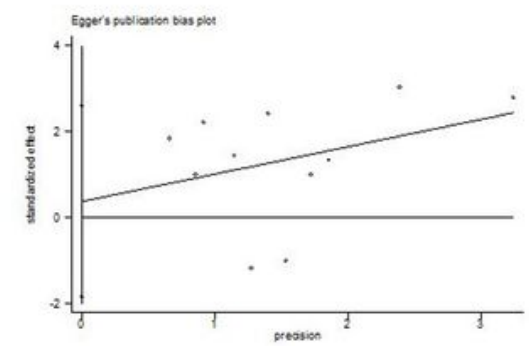

d. Funnel plot

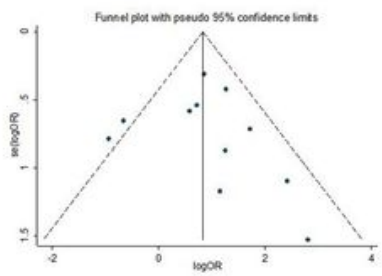

e. Sensitivity analysis

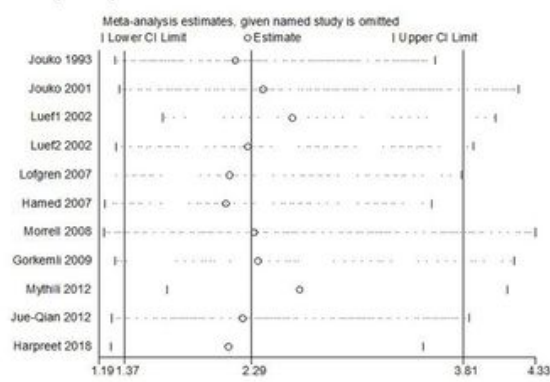

Figure 4

Hyperandrogenism of VPA vs other AEDs 
a. Forest plot

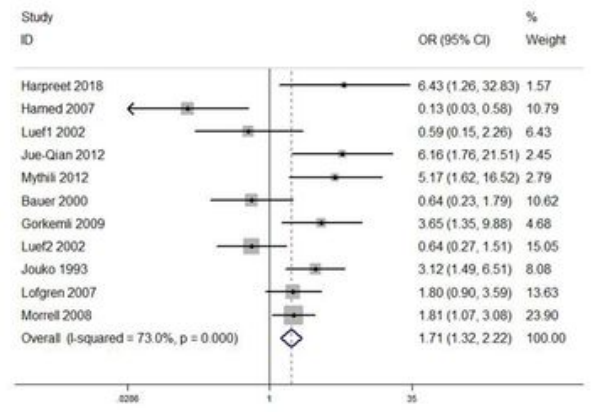

b. Begg's test

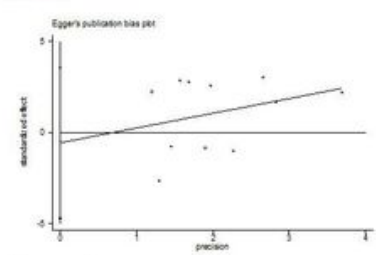

c. Egger's test

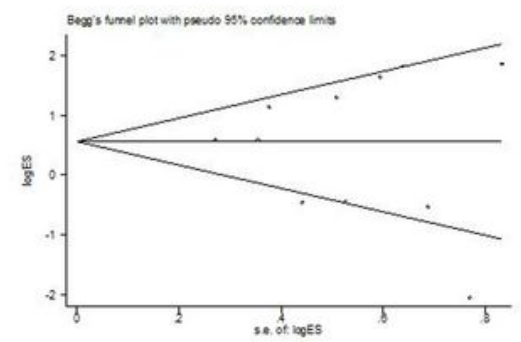

d. Funnel plot

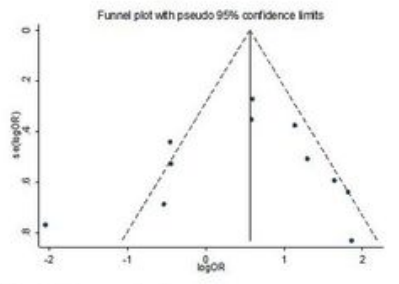

e. Sensitivity analysis

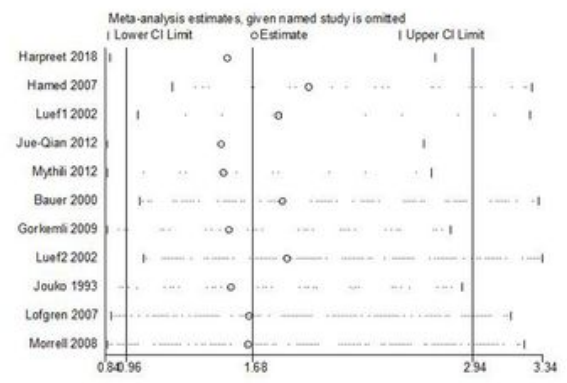

Figure 5

Menstrual disorders of VPA vs other AEDs 